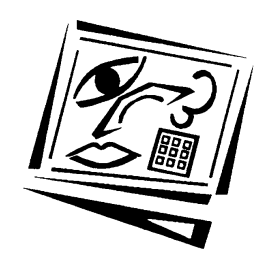

\title{
Responding to the widening participation agenda through improved access to and within 3D virtual learning environments
}

\author{
Denise Wood \\ University of South Australia \\ Julie Willems \\ Monash University
}

\begin{abstract}
The Australian Government's widening participation agenda - also referred to as the social inclusion agenda - considers equity through the triple focus of access, participation and outcomes. These foci are catalysts for re-examining teaching and learning approaches in formal education. This article considers this national refocus and the possibilities for addressing access and equity issues through and within threedimensional virtual learning environments (3DVLEs). The findings of an Australian Learning and Teaching Council (ALTC)-funded project that investigated the potential of an accessible 3DVLE for increasing access and participation of students with disabilities are reported, and strategies for improving outcomes (i.e. retention, success and completion) proposed. The article also highlights some of the remaining challenges with regard to the goal of improving outcomes for under-represented learner groups. The final section of the article identifies areas for further research.
\end{abstract}

\section{Introduction}

The Australian Government's widening participation agenda - also known as the social inclusion agenda - is in response to several reports highlighting the continuing inequalities in access to higher education and associated outcomes, and is a catalyst for reconsidering learning and teaching in the context of formal education (Bradley, Noonan, Nugent \& Scales, 2008; Elliott, 2010; James et al., 2008). This reconsideration is taking place through the lens of equity concerns, and has led to evaluation of current and future practices through the experience of those who are from under-represented and/or disadvantaged groups. While the Australian higher education sector set important precedents in 1990 with the establishment of an advanced equity framework (James et al., 2008), as the Bradley Report (Bradley et al., 2008) notes, "those disadvantaged by the circumstances of their birth: Indigenous people, people with low socio-economic status [SES], and those from regional and remote areas" (p. xii) remain under-represented in higher education. Further, the Bradley Report recommends a continued monitoring of participation rates for other equity groups covered by the policy adopted following the Martin Report (Martin, 1994), namely female students (particularly in non-traditional and postgraduate study), students who have a disability, and students from non-English speaking (NESB) backgrounds (Department of Education, Training and Youth Affairs [DETYA], 1999). 
The growth in popularity of 3D virtual environments (3DVEs) or virtual worlds, combined with increasing ubiquity and pervasiveness of mobile communications, has opened up new possibilities for engaging students from diverse backgrounds through the use of such environments for learning (Willems, 2009). 3DVEs have attracted significant interest from educators across Australasia (see, for example, Gregory et al., 2010, 2011) who are keen to engage their students in a game-like environment that offers the potential for increased flexibility, enhanced collaborative opportunities and a safe environment for experiential learning activities (Wood, 2009a; Wood \& Hopkins, 2008). As Wood (2010) argues, 3DVLEs "have the potential to link those who are isolated by disability, geographical location and social circumstances through the establishment of virtual communities. In this way... [they] can enable people with disabilities to transcend the limitations of their 'actual lives' through virtual space" (p. 19.1).

This article presents the findings from research examining the ways in which 3DVLEs may be able to support the widening participation agenda by improving equity and access for students, especially those from marginalised and/or disadvantaged backgrounds. The research highlights the accessibility limitations of 3DVLEs and explores solutions for improving access, particularly for students with disabilities, together with strategies that can be employed by teachers to increase the participation of such students within these environments. The article also discusses some of the continuing challenges impacting on the ability of educators to respond to an increasingly diverse student population, and looks at the ways in which some of the inequities that exist in the physical world may be perpetuated in 3DVLEs. The Discussion section of the article proposes strategies that can be adopted by educators to maximise the affordances of 3DVLEs in ways that promote and support the widening participation agenda through increased access to and within such flexible learning environments. Finally, the concluding section acknowledges limitations of the reported study and outlines areas demanding further research.

\section{The widening participation agenda}

In the context of education, considerations of equity revolve around those who have been disadvantaged through direct exclusion from existing structures and practices (Byrne, 2005). Equity is a social justice issue, based on the precept that non-dominant groups need to be supported and resourced in order for social justice to be realised (McIntyre, Volkoff, Egg \& Solomon, 2004).

Following concerns during the late 1980s about participation in higher education of a non-representative sample of the broader Australian population, six educationally disadvantaged student groups were noted in the Federal Government's publication $A$ fair chance for all (Department of Employment, Education and Training, 1990). These groups are students from Aboriginal and Torres Strait Islander backgrounds (Indigenous students), women (particularly in non-traditional and postgraduate study), students who have a disability, rural and isolated students, NESB students who have arrived in Australia within the last 10 years, and students with low SES (DETYA, 1999, p. 1). The Australian higher education sector took an important step in 1990 with the establishment of an advanced equity framework recognising the need to cater to these six groups (James et al., 2008), though it was not until four years later, in the Martin Report (Martin, 1994), that the groups were operationally defined. 
However, on an international level, Martin (2010) asserts that despite major inroads being made in approaches to improving access and participation in higher education for some groups, others continue to be severely under-represented. This leads to a situation in which, according to Martin (2010), "the overall concern with achieving greater equity remains an issue on policy agendas, while more precise targets are changing" (p. 23). This shift in precise targets can be seen in government policy over the past decades. The recent Bradley Report into Australian higher education (Bradley et al., 2008) echoes these observations and findings, indicating that while the participation rates of some equity groups have increased, "those disadvantaged by the circumstances of their birth: Indigenous people, people with low socio-economic status, and those from regional and remote areas" (p. xii) remain under-represented. In this refocus on shifting equity targets, the groups have been relabelled as 'underrepresented' groups. Thus, the three 'under-represented' groups that remain of concern in the current context are low-SES students, Indigenous students, and students from regional and remote areas. While no longer a 'precise target', Bradley et al. (2008) recommend continuing to monitor participation rates for the other equity groups covered by the previous policy (Martin, 1994), those being female students (particularly in non-traditional and postgraduate study), students who have a disability, and NESB students (DETYA, 1999).

In addition to the existence of the above mentioned target groups - equity or underrepresented - Willems (2010) has identified equity as a multidimensional phenomenon. Any individual, she argues, irrespective of whether he/she fits one of the Government's recognised and quantified groups, can experience extreme educational disadvantage through the overlay of what she terms 'equity subgroups' (Willems, $2004 a, 2004 b, 2011)$. Through equity overlap and the interplay of equity subgroups, a social gradient of educational disadvantage is formed. This view diverges from perceptions of equity that are based on a common standard for all. As Dempsey and Conway (2005) write, true considerations of equity involve "finding ways in which the effects of individual abilities or disabilities may be addressed so they do not unfairly advantage or disadvantage students in the education system" (p. 161, emphasis added). Hence student equity relates to the access, participation and outcomes (Coram, 2007) of different social groups (Vick, 2001) or individuals (Santiago, Tremblay, Basri \& Arnal, 2008).

Thus, as we have seen in this section, the Australian Government's widening participation agenda is driven by the findings of a number of inquiries and reports pointing to persisting inequalities in the higher education sector (Bradley et al., 2008; Elliott, 2010; Janes et al., 2008). As Australian universities position themselves to respond to the Government's equity targets (Gillard, 2009), there is growing recognition of the challenges facing educators in their attempts to adapt their teaching and learning strategies to address an increasingly diverse student population (Creagh, Nelson \& Clarke, 2011) - and this is especially so in situations of multiple educational disadvantage (Willems, 2010). As Elliott (2010) suggests, in devising strategies to accommodate such a diverse student population, there is a need to overcome a range of barriers to regular on-campus study, such as geographic isolation for students living in remote regions, high mobility of students, particularly among rural Indigenous communities, economic barriers, family issues, and disability-related factors. Flexible learning methods using digital technologies play a key role in expanding the options available for such students, and hold "the potential to include and engage students with multiple and complex needs that typically prevent access to traditional university 
programs" (Elliott, 2010, 'Concluding comments', para. 4). Yet the adoption of such methods and technologies to address disadvantaged students warrants critical attention, especially in relation to individual equity considerations.

\section{The potential of 3DVLEs in formal education}

So, how can 3DVLEs assist in achieving the problematic goal of widening participation and increasing social inclusion in higher education? Our response to this question is guided by a number of key areas that have emerged from an analysis of the literature. We discuss these areas under three headings that are foci in the current conception of equity within Australian higher education: access, participation and outcomes.

3DVLEs and their potential for improving access

Access to higher education is the initial stumbling block for many disadvantaged (equity) students. In terms of quantifying 'access', it is defined by Universities Australia (2008, p. 14) as the "proportion of the equity group among commencing domestic students". Subban (2006, p. 263) states that those "who promote equity must also work hard to open 'spaces' to subordinated groups, providing access where there was none before". 3DVLEs can provide such learning spaces by offering the conduit for improving access for students who have recognised disabilities and represent a subgroup of the total student population. In doing so, however, the technology can also present further barriers for some students. We will now explore the potential of 3DVLE technology for improving access to higher education, and also pinpoint a number of the barriers that exist.

Accessing formal education may prove a continuing challenge for staff and students with disabilities, especially psychiatric disabilities. For psychiatric, emotional and learning disabilities, 3DVEs can provide 'safe' and mediated havens where learning can be optimised without the usual causes for concern of consequences found in the physical educational setting. As an example, Lester (2005) tells of a 3DVE community in which individuals with Asperger Syndrome can practise and improve their social skills within a risk-free environment. The home of this community is the Second Life 'island' of Brigadoon, named after the mythical land in the musical production (Lerner \& Loewe, 1947) and movie (Freed \& Minnelli, 1954) of the same name. The island is "a real-world experiment in social skills made virtual... [it is] a private enclave limited to a select mixture of caregivers and individuals with Asperger Syndrome, a higher functioning form of autism" (Loftus, 2005, para. 3). Its residents, called 'Dooners', have the opportunity to practise skills and build consequence without fear of ramifications that may take place in the 'real world'.

As Wood (2009b, 2010) and Hickey-Moody and Wood (2010) have observed, 3DVEs such as Second Life provide spaces that facilitate varied kinds of engagement for people who identify as disabled. While some users with disabilities find the accessibility challenges associated with navigating 3DVEs disabling and exclusionary, others gain a sense of empowerment through their interactions in the virtual world. For example, Simon Stevens, the founder of Wheelies, a social network of residents and a nightclub in Second Life, enjoys experiencing Second Life in his virtual wheelchair (Deely, 2007, para. 5). Other residents like Susan Brown (see Stein, 2007, para. 31) and Niles Sopor (see Cassidy, 2007, para. 4) prefer to leave their wheelchairs behind and live their 'second lives' as walking avatars. 
Although auditory channels such as the sound and speech capabilities of 3DVEs enable a partial sensory experience for people with visual disabilities, the software does not easily accommodate their needs (Wongtangswad, 2008). This is an equity consideration when shifting to the provision of formal education in the environments. As Kemp and Livingstone (2007, p. 15) observe,

\author{
the user interface currently does not work with any screen-readers. For students with \\ less severe visual impairments, the ability to modify the user interface - to change \\ colours and fonts to less stylish but more readable settings - would be a step in the \\ right direction.
}

There are reports on Second Life Educators (SLED) electronic mailing list suggesting that having sight-affected students and sighted students work together in pairs can help alleviate such problems in the face to face classroom, but the challenges remain in distance learning scenarios (Mirliss, 2006).

\title{
3DVLEs and their potential for improving participation
}

Participation is defined in the Australian context as the "proportion of the equity group among domestic students overall" (Universities Australia, 2008, p. 14). In addition to initial access to higher education, ongoing participation is a major challenge for disadvantaged students. Immersive 3DVEs such as Second Life afford opportunities for practice and feedback via experiential learning, which Kolb (1984, p. 38) defines as "the process whereby knowledge is created through the transformation of experience". Safara (2008, p. 1356) writes that these learning environments provide

\begin{abstract}
a place where all imaginable types of human interaction can be experimented with limited repercussions when something goes wrong. This is unlike the real world as any mistake could be our last.
\end{abstract}

Willems (2009) contends that a major benefit of using 3DVLEs such as Second Life in formal educational contexts is the ability to teach and learn using a wide variety of media, which is an effective method of addressing learning style imbalances. She further posits that such environments provide opportunities to meet differences in the learning styles of a diverse student population, especially in relation to activereflective (Willems, 2008a), visual-verbal (Willems, 2008a) and sequential-global (Willems, 2008b) learning style preferences. With respect to each of these types of preference, respectively, students can have opportunities to reflect on information or be actively involved in a learning task; they can read or hear new information, or see new things from different vantage points; and they can follow a process through from start to finish, or inspect a process as a whole (e.g. when using the avatar's 'flying' mode in Second Life or using the map and mini-map functions to better understand the virtual world layout/landscape).

\section{DVLEs and their potential for improving outcomes}

While, as outlined in the previous sections, there is evidence of 3DVLEs assisting both access and participation for disadvantaged students in higher education, outcomes are often the indicator that administrators and policymakers are most keen to observe. The term 'outcomes' need not necessarily refer exclusively to graduation from an entire degree program, as is the usual consideration; it may also encompass the attainment of a smaller, incremental goals or milestones along the student's journey to reaching that ultimate end, including successful completion of assessment tasks, individual subjects/units of study or a year's sequence. Outcomes can also encompass fulfilment of other, program-specific requirements such as field experiences, work placements, 
capstone projects and submission of a theses or portfolios. Outcomes relate to three operationalised concepts: retention ("the proportion of equity group students who reenrol at an institution in a given year compared with the students who were enrolled in the previous year, less those students who have completed their course"), success ("the mean student progress rate for the previous year for the equity group, this being the proportion of units passed within a year to the total units enrolled") and completion ("the proportion of students completing all the academic requirements of a course") (Universities Australia, 2008, p. 14).

\section{Methodology and participants}

In this and the ensuing sections of the article, we turn our attention to the opportunities and challenges for one particular category of students who are underrepresented or disadvantaged - that is, those with disabilities. We report on a study funded by the Australian Learning and Teaching Council (ALTC) that investigated the potential of 3DVLEs to improve access, participation and outcomes for students with disabilities.

The study consisted of two major stages, the first focusing on access and the second on strategies for enhancing participation. Human Research Ethics Committee approval was obtained at the first author's university prior to the commencement of the project.

A participatory research approach was followed for both stages of the project. The first stage involved the design and development of an accessible, open source 3DVLE viewer (the client application required to connect to the 3DVE) and the development of guidelines for improving access to 3DVLEs for students with disabilities. The approach comprised the following steps:

1. Review of the literature to identify the usability / accessibility challenges;

2. Ethnographic research within Second Life involving participant observation of users' interactions and the conducting of interviews with individuals identifying as disabled in their 'actual' lives;

3. Review of existing accessibility solutions;

4. Development of guidelines for interface design based on the World Wide Web Consortium's (2008) Web Content Accessibility Guidelines (WCAG) 2.0 and informed by the responses of the participants recruited for the project;

5. Design and development of an open source, accessible 3DVLE for use in higher education;

6. Independent usability/accessibility testing of the platform.

Current users of 3DVEs were recruited as paid consultants through a 'notecard' (a virtual item containing text and/or other embedded items) distributed by Virtual Helping Hands (http://www.virtualhelpinghands.org/), a not for profit organisation in Second Life. Participants in the ethnographic study were also given the opportunity to indicate interest in contributing to the evaluation of the open source 3DVLE software produced as part of the project, as well as to the development of guidelines for improving the accessibility of learning and teaching activities conducted in 3DVLEs.

A total of 15 individuals responded to the notecard invitation, including 13 with disabilities (visual and mobility impairments) and 3 who are experts in 3DVLE 
development, but do not identify as having a disability in their 'real' or 'actual' lives. One of the visually impaired respondents is blind. Of the 15 respondents to the invitation who expressed a desire to be contracted to undertake the reviews, 11 signed contracts and completed their reviews, including 8 with disabilities and 3 expert developers.

The second stage of the project focussed on the development of guidelines to increase educational participation of learners with disabilities in 3DVLE activities. The findings from these two stages of the project are briefly presented in the next section. More detailed findings are available in the final report submitted to the ALTC (Wood \& Bloustien, 2012). Other resources and deliverables from the project can be found on the project website at http:/ / www.unisanet.unisa.edu.au/3dvle/.

\section{Results and outcomes}

\section{Access}

\section{Usability/accessibility challenges}

As reported by Wood (2010) and Wood and Bloustien (2012), the first two stages of the research incorporated a review of the literature and an ethnographic study undertaken with Second Life users who identified as people with disabilities in their 'actual' lives. The literature review and the ethnographic research identified the following accessibility challenges associated with 3DVEs:

- The login screen of Second Life is not accessible for visually impaired users who rely on screen-reader software.

- The local chat window in Second Life is not accessible to screen-reader software.

- The user interface of the Second Life viewer is not accessible to screen-reader software and there is limited support for alternative accessing devices.

- There is need for 'tab index' to be incorporated to provide a logical ordering of links and options.

- There is need for the provision of an audio message and a text list of avatars in the vicinity of the user's avatar.

- There is a need for an option enabling users to add descriptive labels for all objects, and longer descriptions for posters and slides that contain text in graphical format (i.e. as images or parts of images).

- There is a need for synchronised streaming captions for videos.

- There is a need for text transcriptions for streaming audio.

The 11 contracted participants were asked to rate the accessibility of currently available standard 3DVE viewers. As Figure 1 shows, only 1 of the participants regarded standard 3DVE viewers as meeting accessibility guidelines. There was 1 participant who did not respond to the question, and 2 explicitly declined to answer it, citing as a reason their inability to use standard viewers due to the nature of their disabilities. Of the remaining respondents, 4 stated the current standard viewers only 'somewhat meet' and 3 stated that they 'do not meet' accessibility guidelines. Consistent with the findings from our review of the literature, more than half of the respondents agreed that the standard 3DVE viewers they had used were not fully accessible for users with disabilities. 


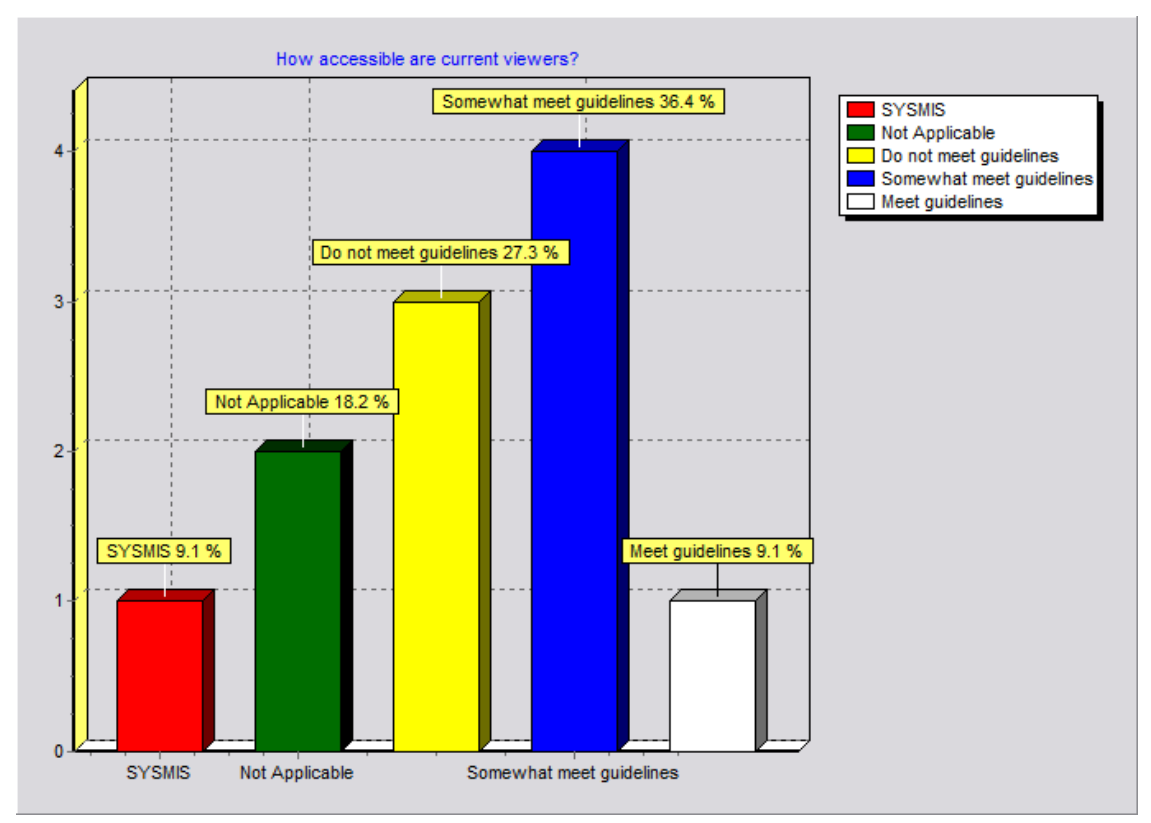

Figure 1: User evaluation of the accessibility of standard 3DVE viewers

Review of existing accessibility solutions

The review of the literature also considered techniques for improving the accessibility of media-rich applications, Web 2.0 technologies and 3DVLEs. This review was complemented with desktop research into available alternative accessible viewers as well as in-world interviews with Second Life community residents identifying as either programmers designing accessibility solutions or people with disabilities who use customised solutions to improve their ability to navigate the virtual world. This ethnographic research uncovered several existing initiatives, many of which the residents of the communities themselves developed. Some of these were:

- The development of non-graphical based viewers (e.g. Radegast http: / / www.radegast.org/);

- The use of Internet Relay Chat (IRC) to enable people with disabilities who cannot attend in-world meetings to participate using a web-based community chat room, such as the system used by GimpGirl (see http:/ / www.gimpgirl.com/), community of women with disabilities with a presence in Second Life;

- The Virtual Guidedog (http:/ / www.virtualguidedog.com/) developed by Virtual Helping Hands, which enables users with vision impairments to navigate in the 3DVE by issuing commands through the chat channel to a virtual 'dog' or 'cane' to find an object or follow an avatar;

- The E.V.A. (Essential Voicechat Advancement) system, which is an in-world, voicebased application that narrates text displayed in the chat channel (see Pasteur, 2008);

- Transcription services provided by Virtual Ability, Inc.

(http:/ / www.virtualability.org/), such as voice-to-text transcription, undertaken manually in real time using typed, meaning-for-meaning text, and text-to-voice conversion, undertaken by transcriptionists who read aloud the text offered by the presenter. 
Design guidelines for accessible 3DVLES

Drawing on the research reported above, the following essential requirements for the design of accessible 3DVLEs were identified:

- Ability of the interface to support a range of input devices;

- Inclusion of styles enabling the customisation of type according to size and colour preferences;

- Incorporation of 'tab index' to establish a logical order between links and options;

- Provision of a text-to-voice feature for chat;

- Provision of an audio message and a text list of avatars in the vicinity;

- Provision of an option to turn off graphics;

- Enforcement of a requirement for users to add descriptive labels for all objects, and longer descriptions for posters and slides containing text in graphical format;

- Provision of text notecards for all objects containing text in graphical format;

- Provision of synchronised streaming captions for videos;

- Provision of text transcriptions for streaming audio;

- Provision of voice-to-text conversion for voice that is exposed to screen readers;

- Inclusion of user help functions;

- Potential to interface with wearable computers;

- Availability of web-browser alternatives to client viewers;

- Accessibility of accompanying website.

Design and development of open-source accessible 3DVLE software

The solution developed through the ALTC-funded project was designed to incorporate these accessibility features, and it builds on and complements the Max Voice text-tospeech technology (see http://www.virtualguidedog.com/tools/) developed by Virtual Helping Hands as part of its Virtual Guidedog project. There are two main components to the system, the first being the integration of text-to-speech and accessible interface controls in AccessGlobe, the custom-built 3DVLE client viewer, and the second of which is a web-based interface enabling a user to participate in synchronous sessions held in the 3DVLE through an accessible web page (for further details, see Wood, 2010, 2011; Wood \& Bloustien, 2012).

The open-source Phoenix viewer (http:/ / www.phoenixviewer.com/) was used as the basis for developing AccessGlobe. Phoenix is popular with Second Life users who prefer the interface layout and design of the original Second Life viewer to those of the current version. Phoenix and AccessGlobe lend themselves well to improving access for users with disabilities as it provides a number of customisable options, which are described below.

- Ability to change colour and size of text. The preferences options provided in Phoenix and AccessGlobe enable users to customise the colour and size of text (Figure 2). This option is important for students with visual impairments and those who are colour blind, as well as for some students with cognitive impairments who may benefit from text that is rendered in a larger size.

- Customisable interface 'skins'. Phoenix and AccessGlobe also provide an option for users to select alternative 'skins' for the viewer interface to improve colour contrast. As Figure 3 shows, this option is an important feature for users with visual disabilities. The 'General' preferences pane also enables users to customise the size of the interface and its elements. 


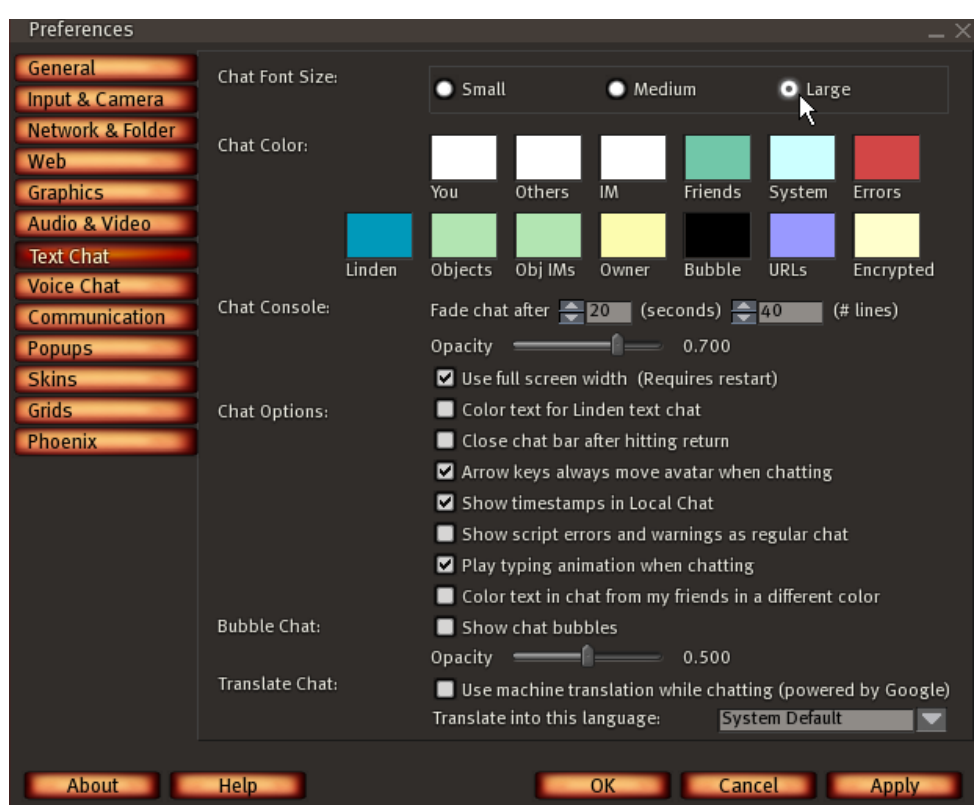

Figure 2: Customising colour and size of text using the AccessGlobe viewer preferences

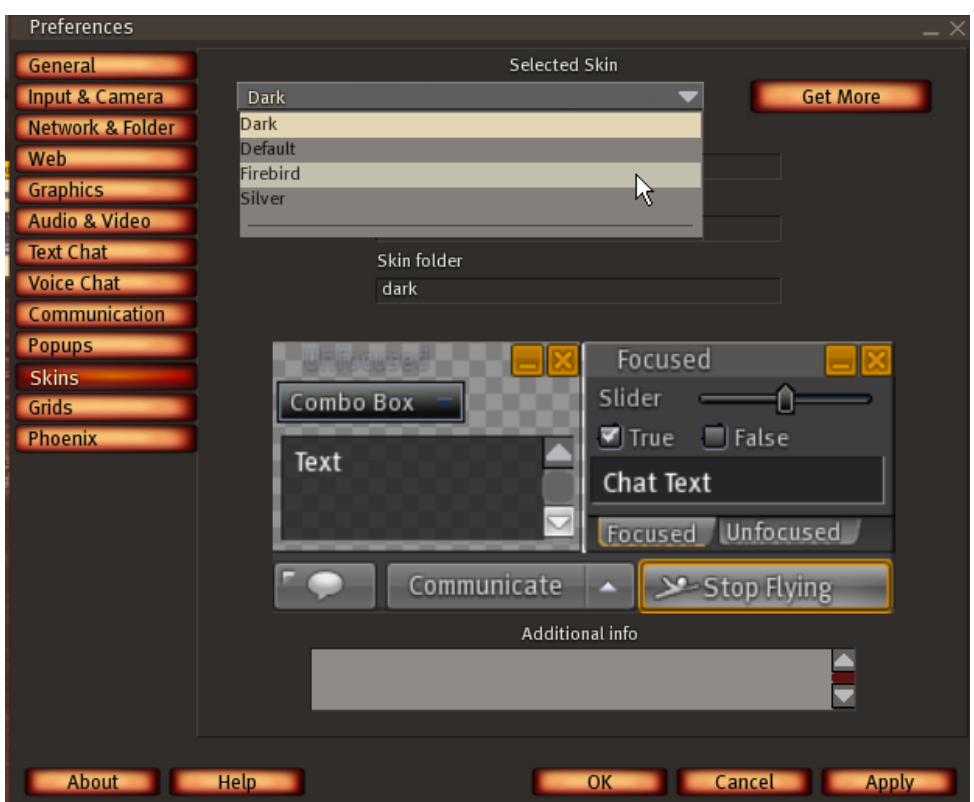

Figure 3: Customisable skins are options in the Phoenix and AccessGlobe viewers

- Ability to turn off graphical elements. Both the Phoenix and AccessGlobe viewers provide an 'advanced' option in the 'Graphics' preference pane (Figure 4) enabling users to select which graphical elements (i.e. particles, sky, clouds, water) they want displayed, and which ones they do not want displayed. This feature can assist users who find flickering or complex graphics displays distracting or disorienting. 
- Spell checking. In Phoenix and AccessGlobe, there is an option to turn spell checking on (Figure 5). This gives students with cognitive impairments (e.g. dyslexia) the ability to detect and correct any errors in their text chat and instant messages (IM) prior to sending. By default, the spell-checker dictionary is based on US English, but the option to load alternative dictionaries is provided.

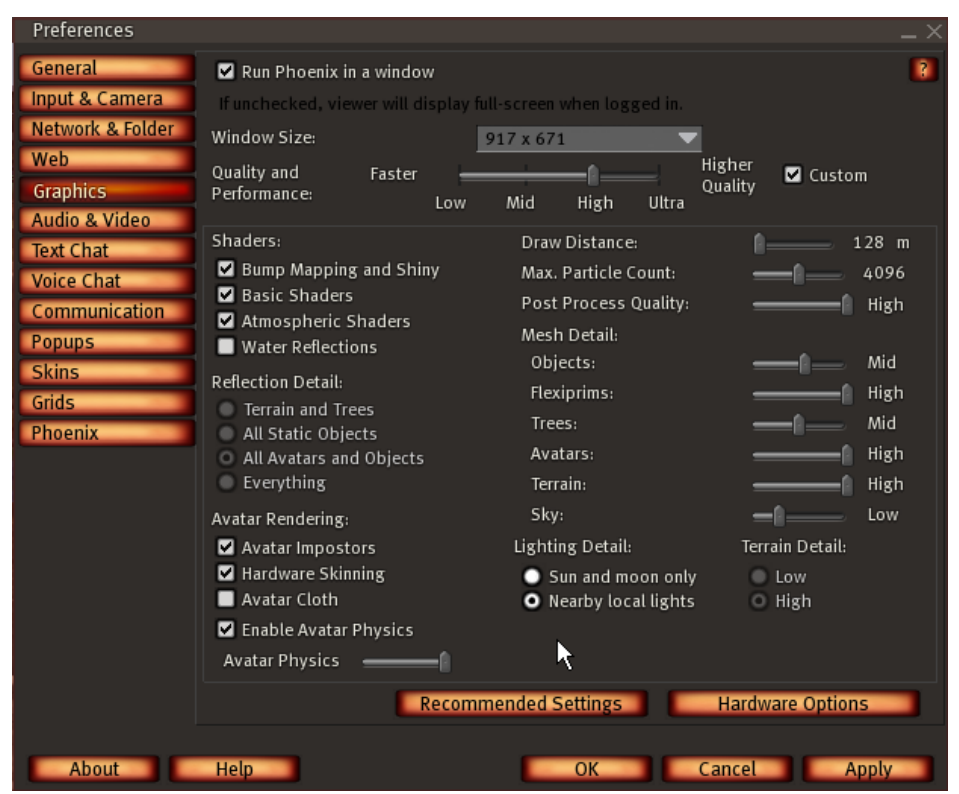

Figure 4: Advanced options in the Phoenix and AccessGlobe viewers allow users to turn off certain graphical elements

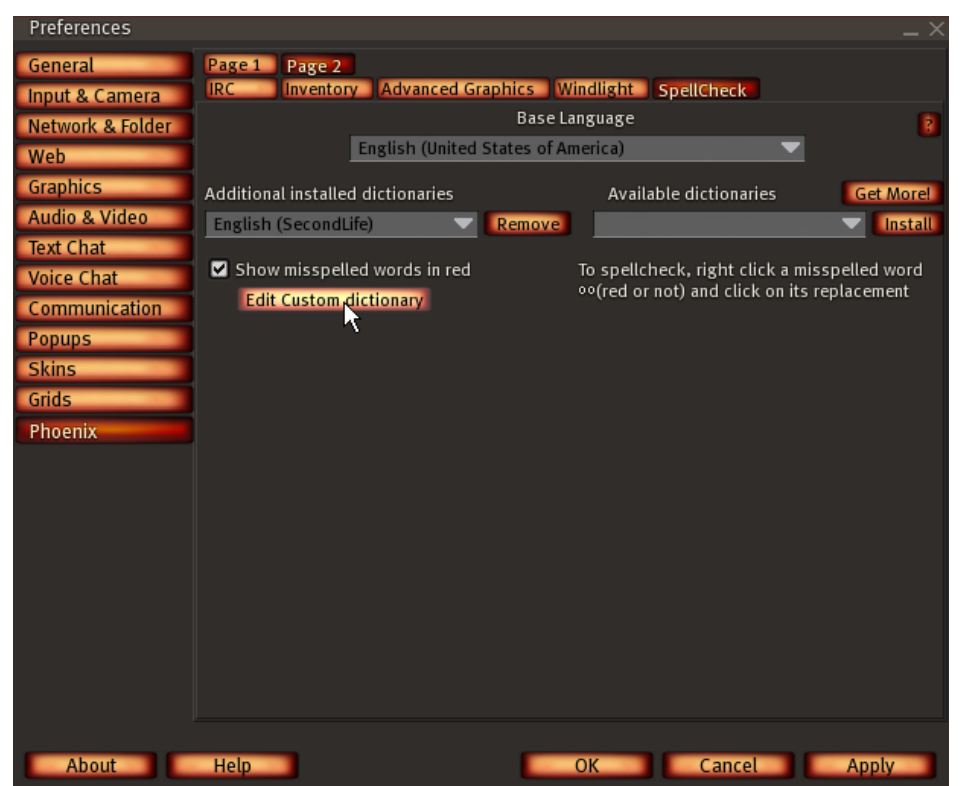

Figure 5: A spell-check option is provided in the Phoenix and AccessGlobe viewers 
- Tab index. Phoenix and AccessGlobe both provide a tab-index feature enabling users to 'tab' between menu options in the viewer (i.e. press the 'tab' key on their keyboard to move from one option to the next). This feature is important for users with mobility impairments who are unable to use a mouse, as well as blind users who rely on spoken output to navigate between menu options.

- Text-to-speech output. AccessGlobe generates text-to-speech output - chat, IM, interface elements and messages are all read aloud, and if the viewer is used in conjunction with Virtual Helping Hands' Max Voice, the names of avatars are all also able to be read aloud. Additionally, Max Voice provides the option for users to hear each character read aloud as they type, using the 'Echo Keys' feature (Figure 6).

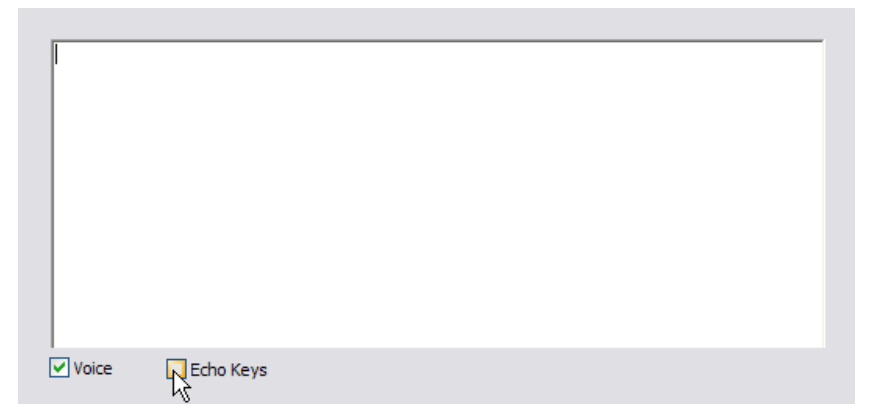

Figure 6: Text-to-voice options provided in the AccessGlobe viewer

The 11 participants were invited to rate the importance of each these features in aiding accessibility for students with disabilities. The majority of them (6 or 54.5\%) reported having five or more years' experience with 3DVEs, with only 1 (an individual with a mobility impairment) claiming being a 'novice' user. Half of the participants identified as Second Life users, with the remaining specifying that they used multiple platforms. The findings are summarised in Table 1.

Table 1: Importance of 3DVLE accessibility features for students with disabilities

\begin{tabular}{|c|c|c|c|c|c|}
\hline Feature & Essential & $\begin{array}{c}\text { Very } \\
\text { important }\end{array}$ & Important & Neutral & $\begin{array}{l}\text { Not very } \\
\text { important }\end{array}$ \\
\hline $\begin{array}{l}\text { Ability for user to change font size and } \\
\text { colour }\end{array}$ & $63.6 \%$ & $36.4 \%$ & & & \\
\hline Customisable interface 'skin' & $36.4 \%$ & $54.5 \%$ & $9.1 \%$ & & \\
\hline Ability to turn off graphical elements & $45.5 \%$ & $27.3 \%$ & $9.1 \%$ & $18.1 \%$ & \\
\hline Avatar's name is read aloud & $9.1 \%$ & $27.3 \%$ & $18.1 \%$ & $36.4 \%$ & $9.1 \%$ \\
\hline $\begin{array}{l}\text { Tab-index functionality to provide } \\
\text { logical order between links and options }\end{array}$ & $54.5 \%$ & $36.4 \%$ & & $9.1 \%$ & \\
\hline
\end{tabular}

Independent reviews conducted by Media Access Australia (Hollier, 2010) and users (including 8 users with disabilities) found that the AccessGlobe viewer, used in conjunction with Virtual Helping Hands' Max Voice technology, significantly improves the accessibility of user experiences in 3DVLEs. As Figure 4 shows, more than half of the reviewers (6 or 54.5\%) saw the AccessGlobe viewer as 'greatly improving' accessibility for users with disabilities, while 4 (36.4\%) saw it as 'improving' accessibility for such users. 
The qualitative comments made by reviewers suggest that they deemed the audio feedback provided in-world to be helpful in enabling users with visual impairments to better communicate via text chat, and to interact more effectively with objects within the 3DVLE. The customisable features such as text size and colour and the incorporation of customisable skins, designed to accommodate visually impaired users not reliant on screen readers, were also highly regarded. The tab-index functionality was seen by users with mobility impairments as well as by the blind user to be an important accessibility feature.

The users and independent evaluator emphasised the importance of providing embedded help functions in-world and via the web portal. While help is currently available via the website, and to a certain extent is also built into the interface of AccessGlobe, as the independent evaluator suggested, people with disabilities are still likely to need assistance in the beginning to ensure they understand how to set up and access the built-in accessibility features. One user with a visual impairment also suggested it would be valuable to have an in-world landing place housing training materials and orientation features.

A number of other features were suggested by the users as being potentially useful additions for improving accessibility. These include:

- Provision of voice-to-text functionality;

- Enhanced accessibility built into mobile viewers for iPad and iPhone devices;

- Descriptive content for audio and video materials (in addition to captions and text transcriptions);

- The ability to stop the built-in voice narrating content;

- Provision of an accessibility items folder in-world;

- Provision of keyboard access to the top-level menu with access-key support.

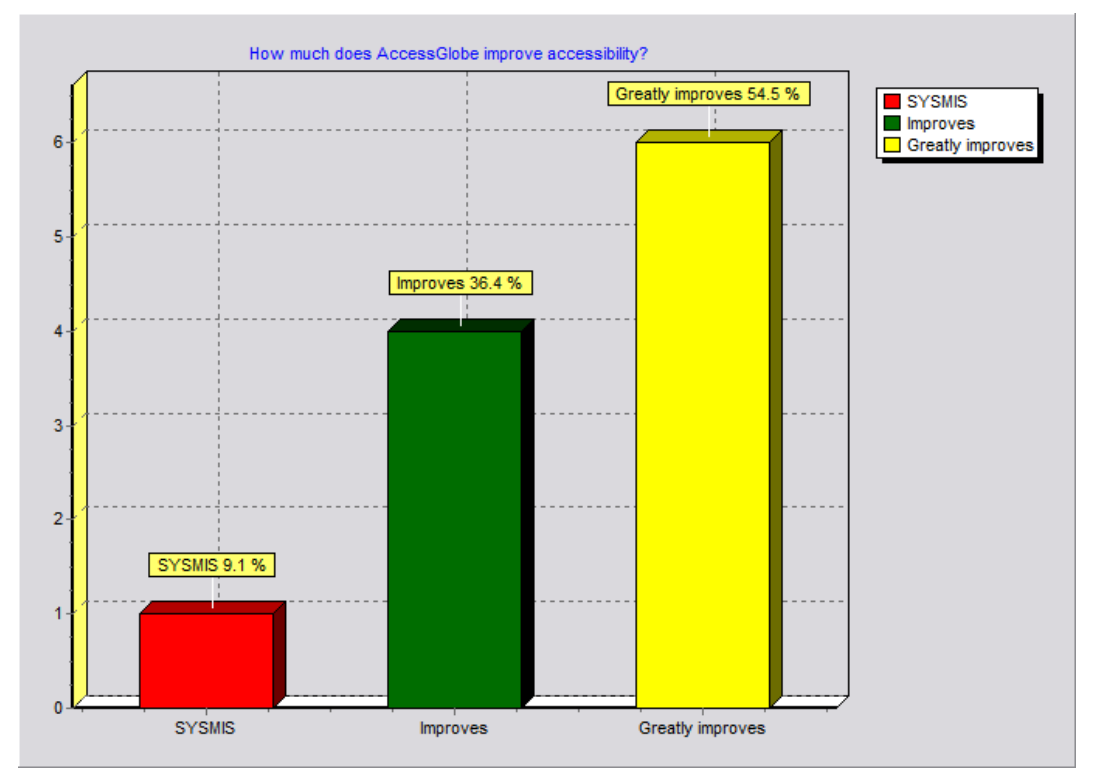

Figure 7: Reviewers' rating of the accessibility of the AccessGlobe viewer 


\section{Participation}

The second stage of the project involved the development of guidelines for educators in terms of strategies they could use to improve the participation of students with disability in 3DVLE-based learning and teaching activities. The development was informed by the eight users with disabilities and three expert developers who participated in the review of AccessGlobe's features.

The participants were asked to rate the usefulness of strategies that may be employed by teachers/facilitators conducting classes in 3DVLEs to improve the participation of students with disabilities. The findings are as follows:

- Providing notecard descriptions to participants: Essential - 27.3\%, Very important $-72.7 \%$;

- Conducting sessions in text chat and voice: Very useful - 6\%, Useful - 18.2\%, Somewhat useful - $18.2 \%$;

- Providing a live captioner during sessions: Essential - 36.4\%, Very important $-18.2 \%$, Important $-27.3 \%$, Not very important $-18.2 \%$;

- Providing text transcriptions for voice and audio: Essential - $44.5 \%$, Very important - $45.5 \%$;

- Providing access to YouTube captions on videos displayed in-world: Most improved - 36.4\%, Very improved - 45.5\%, Improved - $18.2 \%$;

- Ensuring that the virtual space appears accessible: Essential - 27.3\%, Neutral $-27.3 \%$, Important $-27.3 \%$, Not very important $-18.2 \%$.

Other strategies proposed by the participants to improve the accessibility of 3DVLE classes and the participation of students with disabilities attending those classes included:

- Making better use of 'soundscapes' for blind users;

- Providing notes for voice in sync with presentations;

- Providing an option for users to register for events and indicate their accessibility needs in advance;

- Ensuring support (e.g. through mentors) is available during sessions;

- Allowing time for all learners to keep up with the pace of the session;

- Minimising distractions in the virtual space;

- Providing live descriptions of visual content displayed in-world;

- Making available an IRC channel so that users who cannot participate in-world can participate via that channel.

\section{Discussion}

The results reported in the preceding section show that the users who participated in the study regarded the ability to change the size and colour of text, the availability of customisable interface skins, the supplying of notecard descriptions, the conducting of sessions in text chat and voice, and the provision of transcriptions for voice and audio all to be essential, very important or important for students with disabilities undertaking learning and teaching activities in 3DVLEs. They were less consistent in their views on the importance of providing a live captioner during sessions, supplying YouTube captions on videos displayed in-world, and ensuring the virtual space reflects the appearance of accessible spaces in the physical world. 
The mixed response to the question of providing a live captioner during sessions may be a reflection of the range of users, given that no users who identified as being deaf responded to the invitation to participate. Nevertheless, it is noteworthy that all participants regarded the provision of transcriptions to be essential or very important. The issue of providing YouTube captions might have attracted diverse responses because participants did not see the value of showing YouTube videos in-world. Finally, the variety in opinions pertaining to the need for the 3DVE to reflect accessible physical spaces is not surprising, as some users believe the virtual world should not consist of replicas of 'real-world' spaces, while others consider accessible virtual builds essential because they provide a model for others to better understand the real-world accessibility needs of people with disabilities.

Other strategies noted by respondents as offering the potential to improve access and participation for students with disabilities include ensuring that distractions in the virtual space are minimised, allowing sufficient time for all learners to keep pace with the session, and providing voice and text-based descriptions of content within the 3DVE.

Another strategy that could improve the participation of students with disabilities in 3DVLE classes is to provide a dedicated mentor in-world for students who might have specific needs that may make participation difficult. One respondent suggested that this approach could be streamlined if teachers were to provide a means by which students with specific needs could register for in-world classes and provide notification of their needs prior to the session, thereby giving the teacher enough time to organise a mentor or captioner and to make any other necessary arrangements.

Several respondents and the independent reviewer from Media Access Australia emphasised the importance of ensuring there is adequate help available, and also induction material provided to familiarise students with the 3DVLE, as well as the accessibility features available to them. One way in which students can be introduced to the 3DVLE in a non-threatening and paced manner is through the use of an orientation area that steps newcomers to the 3DVLE through tasks requiring them to walk their avatar, fly, use the camera controls, use local text chat and IM options, control their inventory, purchase objects in-world, customise the appearance of their avatar, and change preferences. Figure 8 depicts an orientation region that has been developed to serve this purpose.

As the Media Access Australia reviewer noted (Hollier, 2010), despite the incorporation of accessibility features and options there will likely be some students with disabilities who still require initial assistance in setting up the relevant options in the preferences menu of the viewer prior to participating in 3DVLE activities.

While the research reported in this article involved usability testing of AccessGlobe, the accessible 3DVLE viewer developed through the ALTC-funded project (described in further detail in Wood, 2010 and Wood \& Bloustien, 2012), it was beyond the scope of the study to evaluate the use of AccessGlobe by students actually undertaking classes in a 3DVLE. Similarly, while we have reported the strategies recommended by users of 3DVEs for improving the participation of students with disabilities in 3DVE-based learning activities, formal evaluation of the strategies' impact on student outcomes was not performed. 


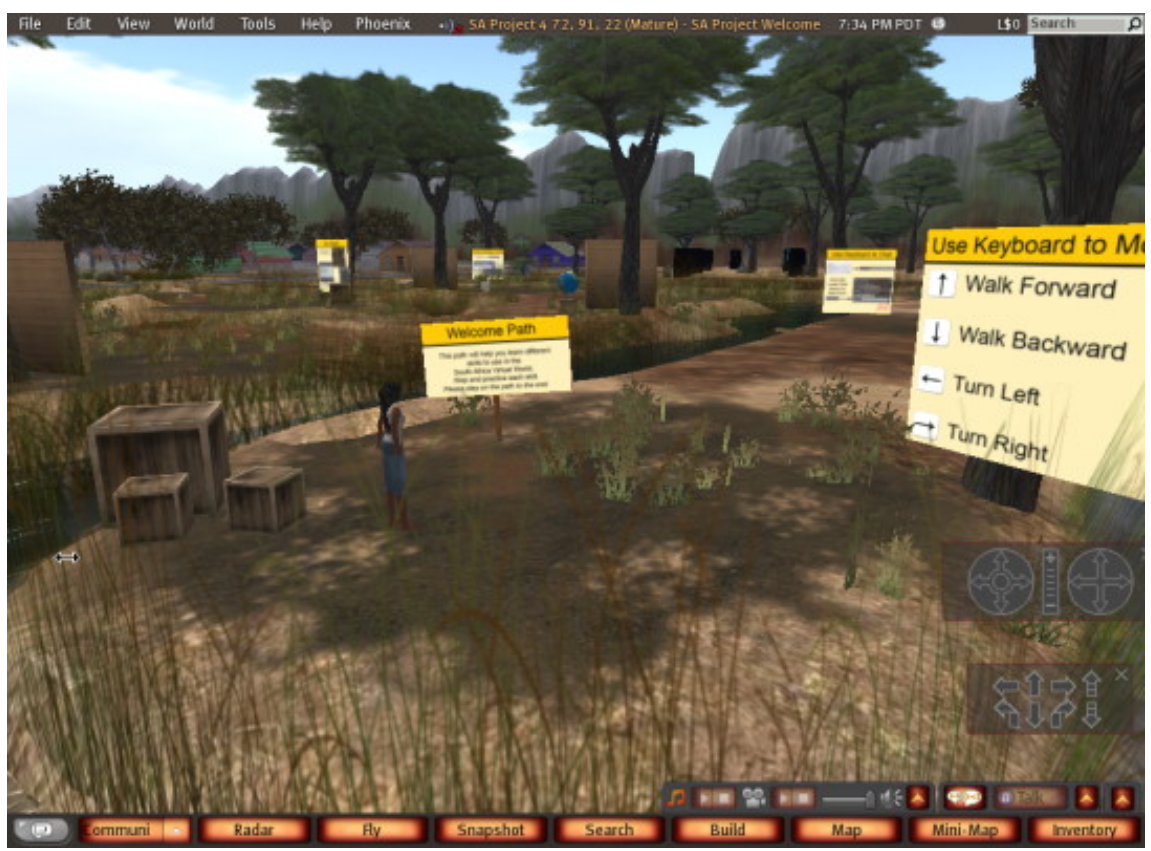

Figure 8: Providing an orientation area for students who are new users of 3DVLEs can help improve access and participation as well as learning outcomes

The present study was largely concerned with technologies and strategies for improving the access and participation of students with disabilities. As such, this article has not fully explored the potential of 3DVLEs for addressing the needs of students from other under-represented or equity groups. Moreover, this article has focussed primarily on access and participation; further research is needed to understand the impact of such strategies on outcomes for students with disabilities and for those from other disadvantaged backgrounds.

\section{Concluding remarks}

The Australian Government has affirmed its commitment to increasing the number of young people, and particularly those from equity groups, attaining a higher education. This article has demonstrated that 3DVLEs have the potential to provide a conduit through which widening participation and increasing social inclusion can be accomplished for students with disabilities.

The review of the literature has illuminated ways in which 3DVLEs may be used to increase access, participation and outcomes for learners with disabilities. It has also identified barriers that prevent the realisation of this goal. The findings reported in this article show that several solutions have already been developed in an effort to improve access to 3DVEs in general for users with disabilities, and these are also being applied in the educational context in hope of improving access for students with disabilities. The research conducted with expert developers as well as with current 3DVE users who have personal experience of disability identified several strategies that can be adopted by teachers to improve the participation of learners with disabilities in 3DVLEs. 
The next step will be to gather empirical data (both qualitative and quantitative) on the effectiveness of 3DVLEs in improving student outcomes, and thus assist the widening participation and social inclusion agenda that is presently a major impetus for reevaluating Australian higher education.

This article has focussed largely on the access and participation issues facing students with disabilities. Further research is needed to investigate the potential of 3DVLEs to improve access, participation and outcomes for students from other disadvantaged backgrounds - including students living in remote regions, students from highly mobile groups, particularly among rural Indigenous communities, and students facing economic hardship - in addition to those impacted by disability-related factors.

\section{Acknowledgments}

The research reported in this article was supported by a grant from the Australian Learning and Teaching Council (ALTC), which was an initiative of the Australian Government Department of Education, Employment and Workplace Relations (DEEWR). The ALTC ceased operations in September 2011, and most of its functions have been transferred to the newly established Office of Learning and Teaching (OLT) within DEEWR. The views expressed in this article do not necessarily reflect the views of the ALTC, OLT and/or DEEWR.

The leaders of the project were Dr Denise Wood and Adjunct Associate Professor Gerry Bloustien of the University of South Australia. The partner institutions involved in the project were Edith Cowan University, Monash University, RMIT University and The University of Sydney in Australia, as well as The University of Sheffield in the UK. The programmer for the project was Charles Morris, Vice-President of Virtual Helping Hands (USA); the assistance of Janyth Ussery, President of Virtual Helping Hands is also acknowledged.

Finally, grateful thanks are extended to the reviewers and copy editors for their guidance in the refinement of the article.

\section{References}

Bradley, D., Noonan, P., Nugent, H. \& Scales, B. (2008). Review of Australian higher education: Final report. Canberra: Department of Education, Employment and Workplace Relations. [viewed 20 May 2011] http:/ / www.deewr.gov.au/HigherEducation/Review / Documents / PDF / Higher\%20Education\%20Review_one\%20document_02.pdf

Byrne, D. (2005). Social exclusion (2nd ed.). Maidenhead, UK: Open University Press.

Cassidy, M. (2007). Flying with disability in Second Life. Eureka Street, 17(8). http: / / www.eurekastreet.com.au / article.aspx?aeid=2787

Coram, S. (2007). 'One for all...': Reconceptualising disadvantage as hierarchical in social, vocational education and training related policy. Just Policy: A Journal of Australian Social Policy, 44, 5-11. http: / / search.informit.com.au / documentSummary;dn=543374115044793;res=IELHSS

Creagh, T. A., Nelson, K. J. \& Clarke, J. A. (2011). Acknowledging social justice and equity through good practice for monitoring student learning engagement in FYE. In J. Thomas (Ed.), Proceedings of the 14th Pacific Rim First Year in Higher Education Conference. Brisbane: Queensland University of Technology.

http: / / www.fyhe.com.au/ past_papers / papers11/FYHE-2011 / content/pdf/13B.pdf 
Deely, L. (2007). Is this a real life, is this just fantasy? The Times, 24 March. [viewed 15 Feb 2008] http: / / women.timesonline.co.uk/tol/life_and_style/women/body_and_soul/article1557980.ece

Dempsey, I. \& Conway, R. (2005). Educational accountability and students with a disability in Australia. Australian Journal of Education, 49(2), 152-168.

Department of Education, Training and Youth Affairs (1999). Equity in higher education. Canberra: DETYA. [viewed 29 Feb 2011] http:/ / www.dest.gov.au/archive/highered/occpaper/99A/equityhe_all.pdf

Department of Employment, Education and Training (1990). A fair chance for all: Higher education that's within everyone's reach. Canberra: Australian Government Publishing Service.

Elliott, A. (2010). Equity, pedagogy and inclusion: Harnessing digital technologies to support students from low socio-economic backgrounds in higher education. Journal of Community Informatics, 6(3). http: / / ci-journal.net/index.php/ciej/article/view/751/643

Freed, A. (Producer) \& Minnelli, V. (Director) (1954). Brigadoon [Motion picture]. Hollywood, CA: Metro-Goldwyn-Mayer.

Gillard, J. (2009). Universities Australia Conference - 4 March 2009 - speech. [viewed 29 Feb 2012] http:/ / ministers.deewr.gov.au/gillard/ universities-australia-conference-4-march-2009-speech

Gregory, B., Gregory, S., Wood, D., Masters, Y., Hillier, M., Stokes-Thompson, F., ...Yusupova, A. (2011). How are Australian higher education institutions contributing to change through innovative teaching and learning in virtual worlds? In Changing demands, changing directions. Proceedings ascilite Hobart 2011 (pp. 475-590). Hobart: University of Tasmania. http:/ / www.ascilite.org.au/conferences/hobart11/downloads/ papers/Gregory-full.pdf

Gregory, S., Lee, M. J. W., Ellis, A., Gregory, B., Wood, D., Hillier, M., ... Dreher, H. (2010). Australian higher education institutions transforming the future of teaching and learning through virtual worlds. In Curriculum, technology \& transformation for an unknown future. Proceedings ascilite Sydney 2010 (pp. 399-415). Brisbane: The University of Queensland. http: / / www.ascilite.org.au / conferences / sydney $10 /$ Ascilite $\% 20$ conference $\% 20$ proceedings $\% 202010 /$ Gregory-full.pdf

Hickey-Moody, A. \& Wood, D. (2010). Ethics in Second Life: Difference, desire and the production of subjectivity. In C. Wankel \& S. Malleck (Eds), Emerging ethical issues of life in virtual worlds (pp. 169-191). Charlotte, NC: Information Age.

Hollier, S. (2010). Website accessibility overview: Second Life accessible web interface. Sydney: Media Access Australia. http:/ / www.docstoc.com/docs/87336219/ downloaded-from-here-for-review

James, R., Bexley, E., Anderson, M., Devlin, M., Garnett, R., Marginson, S. \& Maxwell, L. (2008). Participation and equity: A review of the participation in higher education of people from low socioeconomic backgrounds and Indigenous people. Melbourne: Centre for the Study of Higher Education, The University of Melbourne. [viewed 20 May 2011] http: / / union.unimelb.edu.au/file_download/337

Kemp, J. \& Livingstone, D. (2007). Putting a Second Life 'metaverse' skin on learning management systems. In D. Livingstone \& J. Kemp (Eds), Proceedings of the Second Life Education Workshop at the Second Life Community Convention San Francisco (pp. 13-18). Paisley, UK: University of Paisley. http:/ / www.simteach.com/SLCC06/slcc2006-proceedings.pdf

Kolb, D. A. (1984). Experiential learning: Experience as the source of learning and development. Englewood Cliffs, NJ: Prentice Hall.

Lerner, A. J. (Writer and Lyricist) \& Loewe, F. (Composer) (1947). Brigadoon: Original Broadway cast recording [CD]. Hollywood, CA: Metro-Goldwyn-Mayer. 
Lester, J. (2005). About Brigadoon. [viewed 6 Jun 2011]

http: / / braintalk.blogs.com/brigadoon/2005/01/about_brigadoon.html

Loftus, T. (2005, 25 Feb). Virtual world teaches real-world skills: Game helps people with Asperger's practice socializing. msnbc.com. http:/ / www.msnbc.msn.com/id/7012645 [viewed 17 Aug 2009]

Martin, L. M. (1994). Equity and general performance indicators in higher education. Canberra: Australian Government Publishing Service.

Martin, M. (2010). Equity and quality assurance: Can they come together? An introduction to the problematic. In M. Martin (Ed.), Equity and quality assurance: A marriage of two minds (pp. 2337). Paris: International Institute for Educational Planning. http: / / unesdoc.unesco.org/images / 0018/001871/187184e.pdf

McIntyre, J., Volkoff, V., Egg, M. \& Solomon, N. (2004). Understanding equity strategies of training providers. Adelaide: Australian National Training Authority. [viewed 29 Feb 2012] http: / / www.ncver.edu.au / popups/limit_download.php?file=research / proj/nr9037.pdf

Mirliss, D. (2006). People with visual disabilities in Second Life. Message posted to the Second Life Educators (SLED) electronic mailing list, 30 July. [viewed 20 Aug 2009] https: / / lists.secondlife.com/pipermail/educators/2006-July / 001718.html

Pasteur, E. (2008). Second Life text-to-chat software: E.V.A. [viewed 10 Mar 2012] http: / / eloisepasteur.net/blog/index.php? / archives/190-Second-Life-text-to-chat-softwareE.V.A..html

Safara, S. (2008, 17-21 Nov). The pros and cons of SL as a learning environment. Presentation delivered as part of a symposium titled 'Second Life application and its potential for higher education, K-12 educators, trainers and librarians' at the World Conference on E-Learning in Corporate, Government, Healthcare, and Higher Education 2008, Las Vegas, NV. http: / / www.editlib.org/p/29819

Santiago, P., Tremblay, K., Basri, E. \& Arnal, E. (2008). Tertiary education for the knowledge society. Vol. 2 Special features: Equity, innovation, labour market, internationalisation. Paris: Organisation for Economic Co-operation and Development. [viewed 29 Feb 2012]

http:/ / www.nemzig.bme.hu/nki/OECD/OECD_2.pdf

Stein, R. (2007). Online avatars are helping the disabled fight back. Nashua Telegraph, 5 November. [viewed 15 Feb 2008] http:/ / www.nashuatelegraph.com/apps/pbcs.dll/ article?AID=/20071125/HEALTH/311250005/-1/ health

Subban, P. (2006). Differentiated instruction: A research basis. International Education Journal, 7(7), 935-947. http:/ / ehlt.flinders.edu.au/education/iej/articles/v7n7/Subban/paper.pdf

Universities Australia (2008). Advancing equity and participation in Australasian higher education: Action to address participation and equity levels in higher education of people from low socioeconomic backgrounds and Indigenous people. Canberra: Universities Australia. http:/ / www.universitiesaustralia.edu.au/resources/63/ 83 [viewed 2 Nov 2011]

Vick, M. (2001). Schools and society: Changes and continuities. In J. Allen (Ed.), Sociology of education: Possibilities and practices (pp. 41-64). Katoomba, Australia: Social Science Press.

Willems, J. (2004a). Looking from the outside in: The issue of equal access to computer-mediated learning by distance learners in higher education. Unpublished Masters thesis, University of New England, Armidale, Australia. 
Willems, J. (2004b). The issue of equal access to computer-mediated learning in distance education. In N. Carrington (Ed.), Exploring integrated learning environments. Proceedings of the Online Learning and Teaching Conference 2004 (pp. 203-210). Brisbane: Queensland University of Technology.

Willems, J. (2008a). From sequential to global: Exploring the landscapes of neomillennial learners. In Hello! Where are you in the landscape of educational technology? Proceedings ascilite Melbourne 2008 (pp. 1103-1113). Melbourne: Deakin University. http:/ / www.ascilite.org.au/conferences/melbourne08/ procs/ willems.pdf

Willems, J. (2008b). Beyond words alone: Considering the role of visual images in e-learning design and related copyright issues. In C. J. Bonk, M. M. Lee \& T. Reynolds (Eds.), Proceedings of World Conference on E-Learning in Corporate, Government, Healthcare, and Higher Education 2008 (pp. 2329-2338). Chesapeake, VA: Association for the Advancement of Computers in Education. http:/ / www.editlib.org/p/30000

Willems, J. (2009). Different spaces but same places: Possibilities, pitfalls and persistent practices in Second Life. In Same places, different spaces. Proceedings ascilite Auckland 2009 (pp. 1109-1120). Auckland: The University of Auckland and Auckland University of Technology. http:/ / www.ascilite.org.au/conferences/auckland09/procs/willems.pdf

Willems, J. (2010). The Equity Raw-Score Matrix - a multidimensional indicator of potential disadvantage in higher education. Higher Education Research and Development, 29(6), 603-621. http: / / dx.doi.org/10.1080/07294361003592058

Willems, J. (2011). Equity: A key benchmark for students and staff in an era of changing demands, changing directions. In Changing demands, changing directions. Proceedings ascilite Hobart 2011 (pp. 1305-1318). Hobart: University of Tasmania. http: / / www.ascilite.org.au/conferences/hobart11/downloads/ papers/Willems-full.pdf

Wongtangswad, J. (2008). Uses of Second Life in higher education: Three successful cases. In C. J. Bonk, M. M. Lee \& T. Reynolds (Eds), World Conference on E-Learning in Corporate, Government, Healthcare, and Higher Education 2008 (pp. 1389-1391). Chesapeake, VA: Association for the Advancement of Computers in Education. http:/ / www.editlib.org/p/29825

Wood, D. (2009a). Experiential learning through 'real world' placements undertaken in 3D 'virtual world' spaces. In Same places, different spaces. Proceedings ascilite Auckland 2009 (pp. 1121-1129). Auckland: The University of Auckland and Auckland University of Technology. http: / / www.ascilite.org.au/conferences/auckland09/procs/wood.pdf

Wood, D. (2009b). Real life access to 'Second Life' worlds: The potential, the problems and the possibilities for a barrier-free future. The International Journal of Diversity in Organizations, Communities and Nations, 8(6), 139-148.

http:/ / ijd.cgpublisher.com/product/ pub.29/ prod.787

Wood, D. (2010). Communicating in virtual worlds through an accessible Web 2.0 solution. Telecommunications Journal of Australia, 60(2), 19.1-19.16. http:/ / www.tja.org.au/index.php/tja/article/view/46/

Wood, D. (2011). The design of inclusive curricula for multi-user virtual environments: A framework for developers and educators. ICST Transactions on e-Education and e-Learning, 11(7-9). http: / / dx.doi.org/10.4108/icst.trans.eeel.2011.e6

Wood, D. \& Bloustien, G. (2012). Facilitating flexible, enquiry-based experiential learning through an accessible open source 3D virtual learning environment: Final report. Sydney: Australian Learning and Teaching Council. 
Wood, D. \& Hopkins, L. (2008). 3D virtual environments: Businesses are ready but are our 'digital natives' prepared for changing landscapes? In Hello! Where are you in the landscape of educational technology? Proceedings ascilite Melbourne 2008 (pp. 1137-1146). Melbourne: Deakin University. http: / / www.ascilite.org.au/ conferences/melbourne08/procs/wood-2.pdf

World Wide Web Consortium (2008). Web Content Accessibility Guidelines (WCAG) 2.0. http: / / www.w3.org/TR/WCAG20 [viewed 2 Nov 2011]

Authors: Dr Denise Wood, Senior Lecturer in Media Arts

School of Communication, International Studies and Languages

University of South Australia, GPO Box 2471, Adelaide, SA 5001, Australia

Email: denise.wood@unisa.edu.au

Denise's research focusses on the use of Web 2.0 and 3D virtual environments/worlds for experiential learning, and to increase the social and educational participation of children and young people with disabilities. She has been the project leader of three Australian Learning and Teaching Council (ALTC)-funded projects and is a member of the Australian Communications Consumer Action Network (ACCAN) Standing Advisory Committee on Disability Issues. Denise's work in innovative teaching and learning and in accessibility solutions for students with disabilities has been recognised with several awards, including an SA Great Award, an ALTC citation for outstanding contributions to student learning, and the inaugural 2010 Telstra-TJA Christopher Newell Prize for Telecommunications and Disability. Denise is an Associate Editor for the journal Higher Education Research and Development.

Dr Julie Willems, E-Learning Designer/Educational Developer Department of Rural and Indigenous Health, Monash University PO Box 973, Moe, VIC 3825, Australia

Email: julie.willems@monash.edu Web: http:/ / wikieducator.org/User:Julie_Willems

Julie holds qualifications in nursing, the humanities and education. She has worked in all education sectors in Australia including secondary, community, TAFE and higher education, and in face-to-face, virtual, flexible and online contexts in the latter. Her research examines equity, access and diversity in various contexts of education, including distance, flexible, mobile, virtual and e-learning, in addition to the technologies of Web 2.0. Julie serves on the Executive Committee of the Open and Distance Learning Association of Australia (ODLAA).

Please cite as: Wood, D. \& Willems, J. (2012). Responding to the widening participation agenda through improved access to and within 3D virtual learning environments. In M. J. W. Lee, B. Dalgarno \& H. Farley (Eds), Virtual worlds in tertiary education: An Australasian perspective. Australasian Journal of Educational Technology, 28(Special issue, 3), 459-479.

http: / / www.ascilite.org.au/ajet/ajet28/wood.html 